\title{
A utilização da técnica de CRISPR-CAS9 na Terapia Gênica
}

\author{
The use of CRISPR-CAS9 Technique in Gene Therapy \\ El uso de la tecnica CRISPR-CAS9 en Terapia Génica
}

Recebido: 14/10/2021 | Revisado: 22/10/2021 | Aceito: 22/10/2021 | Publicado: 25/10/2021

\author{
Vinicius Alves Bernardes \\ ORCID: https://orcid.org/0000-0001-9355-7905 \\ Instituto Educacional Santa Catarina, Brasil \\ E-mail: vinavacina@hotmail.com \\ Gabriele Machado Rodrigues \\ ORCID: https://orcid.org/0000-0002-4149-5025 \\ Instituto Educacional Santa Catarina, Brasil \\ E-mail: gabriele.maro.17@gmail.com \\ Mara Régina Lucene Cabral \\ ORCID: https://orcid.org/0000-0003-2739-7231 \\ Instituto Educacional Santa Catarina, Brasil \\ E-mail: mararegina.uft@gmail.com \\ Liberta Lamarta Favoritto Garcia Neres \\ ORCID: https://orcid.org/0000-0003-1327-605X \\ Instituto Educacional Santa Catarina, Brasil \\ E-mail: liberta.neres@iescfag.edu.br
}

\begin{abstract}
Resumo
A técnica CRISPR-Cas9 tem sido bastante estudada ultimamente e tornou-se uma ferramenta revolucionária no campo da genética, principalmente nas edições e terapias. Trata-se de um mecanismo de defesa encontrado nas bactérias que cliva um pedaço de DNA específico do bacteriófago e agrega-o no DNA da própria bactéria. Ao estudar o comportamento e a eficácia desta técnica nas bactérias, cientistas promoveram estudos para a utilização em laboratório e descobriram que poderia ser usada para a edição genética de forma geral, mais precisa e barata. O maior desafio da utilização da CRISPR-Cas9 encontra-se na praticabilidade da técnica em seres humanos visto que existe o risco do mau uso para fins egoístas que possam trazer um desequilíbrio enorme na sociedade. O objetivo deste trabalho é apontar o progresso positivo da terapia gênica e o impacto positivo de uma nova técnica inovadora capaz de trazer grandes benefícios devido sua simplicidade em trabalhar numa larga escala de genomas, facilitando a prevenção de doenças genéticas inatas ou adquiridas. Foi feito um levantamento bibliográfico de artigos de até 05 anos atrás em plataformas de pesquisa, tanto em língua inglesa quanto em língua portuguesa. Concluiu-se então que a terapia gênica traz enormes benefícios para a sociedade em geral se usada legalmente aprovada, regulada e monitorada, visando o bem-estar e a saúde das populações.
\end{abstract}

Palavras-chave: CRISPR/Cas9; Edição genética; Terapia gênica; Bioética.

\begin{abstract}
The CRISPR-Cas9 technique has been widely studied lately and has become a revolutionary tool in the field of genetics, especially in editions and therapies. This is a defense mechanism found in bacteria that cleaves a specific piece of DNA from the bacteriophage and aggregates it into the bacteria's own DNA. By studying the behavior and effectiveness of this technique in bacteria, scientists carried out studies for use in the laboratory and found that it could be used for gene editing in a general, more accurate and cheaper way. The biggest challenge in using CRISPRCas9 lies in the practicality of the technique in human beings, since there is a risk of misuse for selfish purposes that could bring a huge imbalance in society. The objective of this work is to point out the positive progress of gene therapy and the positive impact of a new innovative technique capable of bringing great benefits due to its simplicity in working on a large scale of genomes, facilitating the prevention of innate or acquired genetic diseases. A bibliographic survey of articles from up to 05 years ago was carried out on research platforms, both in English and in Portuguese. It was then concluded that gene therapy brings enormous benefits to society in general if used legally approved, regulated and monitored, aiming at the well-being and health of populations.
\end{abstract}

Keywords: CRISPR/Cas9; Genetic edition; Gene therapy; Bioethic.

\section{Resumen}

La técnica CRISPR-Cas9 ha sido ampliamente estudiada últimamente y se ha convertido en una herramienta revolucionaria en el campo de la genética, especialmente en ediciones y terapias. Este es un mecanismo de defensa que se encuentra en las bacterias y que escinde un fragmento específico de ADN del bacteriófago y lo agrega al ADN de la propia bacteria. Al estudiar el comportamiento y la efectividad de esta técnica en bacterias, los científicos 
llevaron a cabo estudios para su uso en el laboratorio y encontraron que podría usarse para la edición de genes de una manera general, más precisa y más barata. El mayor desafío en el uso de CRISPR-Cas9 radica en la practicidad de la técnica en los seres humanos, ya que existe el riesgo de un mal uso con fines egoístas que podría traer un gran desequilibrio en la sociedad. El objetivo de este trabajo es señalar el avance positivo de la terapia génica y el impacto positivo de una nueva técnica innovadora capaz de aportar grandes beneficios por su sencillez en el trabajo a gran escala de genomas, facilitando la prevención de enfermedades genéticas innatas o adquiridas. enfermedades. Se realizó un relevamiento bibliográfico de artículos de hasta hace 05 años en plataformas de investigación, tanto en inglés como en portugués. Luego se llegó a la conclusión de que la terapia génica aporta enormes beneficios a la sociedad en general si se utiliza legalmente aprobada, regulada y monitoreada, con el objetivo del bienestar y la salud de las poblaciones.

Palabras clave: CRISPR/Cas9; Edición de genes; Terapia génica; Bioética.

\section{Introdução}

A terapia genética, a edição e manipulação do genoma humano, a ativação, inibição, reparo ou correção de um lócus do DNA e a possibilidade de curar doenças genéticas que antes se achavam impossíveis, com o avanço da tecnologia, ciência e medicina tornam-se cada vez mais reais, principalmente com a descoberta da ferramenta CRISPR-Cas9 encontrada em bactérias como defesa contra elementos invasores (Lins et. al, 2018).

Em suma, tal ferramenta permite fazer a substituição de elementos da cadeia de DNA por outros, corrigindo erros genéticos ou inserindo carácteres benéficos, inibindo determinado códon ou o ativando, segundo o desejo do aplicador (Ramos, 2016; Sganzerla \& Pessini, 2020). Foi primeiramente encontrado como um mecanismo de defesa nas bactérias como a Streptococcus Pyogenes, onde seu sistema imunológico adaptativo detecta o DNA viral e envia a enzima Cas9 que precisamente cliva e degrada esse DNA invasor, agregando ao DNA da própria bactéria em repetições palindrômicas curtas, agrupadas e regularmente interespaçadas (CRISPR, em inglês Clustered Regularly Interspaced Short Palindromic Repeats) (Le Rhun et. Al, 2019).

Assim sendo, com a CRISPR-Cas9 é possível alterar a informação genética, promover um reparo de um gene mutado causador de uma doença, modificar de forma precisa genes de organismos além do ser humano, como insetos, plantas, répteis, peixes, e reverter os sintomas de doença em um ser vivo (Gonzaga e Ramos, 2018). O aprofundamento de estudo e ensaios por parte da comunidade científica debaixo da boa prática da ética no que tange edição de genoma humano, pode vir como um efeito extremamente benéfico para a sociedade, principalmente para os que sobrevivem de medicamentos e terapias dispendiosas por possuir doença incurável. A exemplo, estudos estão sendo feitos acerca da possibilidade, aplicabilidade clínica e eficácia da CRISPR-Cas9 para o tratamento da anemia falciforme e que já é possível constatar um grande potencial no uso desta técnica para o tratamento, possibilitando não só um tratamento para anemia falciforme, mas visando sempre a melhoria da sociedade e aqueles que não possuem condições financeiras para suportar o fardo de se manter vivo com o peso de outras doenças (Mataveia, 2020). Isso auxilia no desenvolvimento de tecnologias avançadas a serviço da saúde pública para o bem-estar social e marca uma nova etapa da ciência e medicina, permitindo grandes avanços da engenharia genética. $\mathrm{O}$ grande desafio que a CRISPR-Cas9 tem que superar é a questão de qual o limite que engenharia genética pode interferir no ser humano, o que fere diretamente na bioética.

A bioética surgiu das preocupações inerentes ao futuro das biotecnologias que avançam cada vez mais, juntamente com o crescimento da ciência e a ampliação do conhecimento, colocando em risco a própria vida na terra. Não há como negar que, em nome da ciência, várias pessoas fizeram experimentos em seres humanos, e coube à bioética limitar essas ações e apresentar os dilemas filosóficos a respeito do valor do ser humano (Nascimento, 2020). Apesar de todo entusiasmo, a referida técnica não corrobora com a maioria das questões da bioética, e faz-se necessário clarificar todo o mecanismo de utilização para poder progredir (Dias \& Dias, 2018). 
Dentro da biomedicina, geneticistas e biólogos moleculares vem trabalhando com edição genética (com desenvolvimento de novas técnicas mais seguras), com aconselhamento, terapias gênicas e estudos clínicos (Fernandes, 2020). O profissional biomédico, como cientista e pesquisador, possui um grande potencial no desenvolvimento da CRISPR-Cas9 devido ao seu enorme conhecimento sobre biologia molecular, genética, biossegurança e bioética, podendo trabalhar em laboratórios de pesquisa de engenharia genética e biologia molecular e agregando ideias que possam ser eficientes para novas formas de utilização da edição genética (Barboza et. al, 2020). O que motivou a escolha do tema foi a possibilidade de criar uma sociedade em que pessoas não tenham mais doenças incuráveis, sendo rejeitadas e muitas das vezes prejudicadas pela própria sociedade. Baseado nisso, o objetivo geral do presente estudo trata-se de explanar o uso positivo da CRISPR-Cas9 em suas implicações legais, histórico e esperança para um futuro em que edição de genes seja algo favorável, saudável e aceitável.

\section{Metodologia}

A metodologia usada para a realização deste trabalho foi baseada revisão integrativa de literatura em artigos científicos em plataformas de pesquisas como Scielo, Google Acadêmico, BDTD, SIBI e Pubmed. Dentre as palavras chaves utilizadas são CRISPR/Cas9, Edição genética, Terapia gênica, Ética e bioética. A documentação de todos esses dados foi em estudos recentes de até 05 anos atrás (2016-2021) em artigos de língua portuguesa e inglesa, e em publicações antigas com materiais de extrema importância.

De acordo com Mendes et. al (2019), a revisão integrativa “[...] possibilita a síntese de conhecimento sobre o tópico de interesse delimitado na área da saúde, a qual pode contribuir com recomendações pautadas em resultados de pesquisas para a prática clínica, bem como na identificação de lacunas do conhecimento direcionando o desenvolvimento de pesquisas futuras." Basicamente, a revisão integrativa da literatura é um método que permite uma sinopse de informação ampla sobre um determinado tema e a assimilação dos resultados de estudos significativos na prática. É um método que agiliza e viabiliza a incorporação das evidências (Sousa et. al, 2017).

A revisão integrativa de literatura é mais eficaz pois fornece informações importantes sobre a investigação atual de um tópico e pode recomendar direções futuras de pesquisa, diminuindo a ocorrência de desvios (Cronin e George, 2020). É interessante dizer que a diversidade na composição de uma amostra utilizando a revisão integrativa fornece uma exposição completa de conceitos, teorias, problemas e conclusões ao objeto de estudo escolhido, proporcionando um olhar mais científico no trabalho.

\section{Resultados e Discussão}

Conforme citado antes, o mecanismo CRISPR-Cas9 proveio de estudos de defesas das bactérias contra DNA invasor onde a enzima Cas9, que é responsável por clivar o DNA, recebe ordens de uma coleção de sequências de DNA chamadas CRISPR para, juntamente com um RNA guia, formar um complexo e ir até ao sítio exato realizar a edição (Lins et. al, 2018). Parte do material genético do invasor é preservado em forma de memória e se a bactéria sofrer um novo ataque pela mesma espécie de invasor, os sistemas de defesa, juntamente com o mecanismo CRISPR-Cas9, identificam e degradam o invasor de forma mais rápida (Reis et. al 2020). Apesar de ter sido descoberta nos anos 80, foi apenas no ano de 2012 que duas pesquisadoras, Jennifer Doudna e Emmanuelle Charpentier, elucidaram o uso do mecanismo e sugeriram que poderia ser usado para edição de genomas, tornando CRISPR-Cas9 a ferramenta mais utilizada para edição de genes em praticamente quase todos os laboratórios de biologia molecular do mundo, em apenas poucos anos (Dounda e Charpentier, 2020). Segundo You et. al (2019) "[...] o sistema CRISPR-Cas9 pode ser aproveitado para estudar mecanismos moleculares no processo de gênese e progressão da doença e, mais significativamente, para remediar ou corrigir mutações genéticas causadoras de doenças para aplicações translacionais clínicas em grandes doenças humanas, especialmente cânceres”. Assim sendo, tem-se não só uma 
ferramenta para tratamento e pesquisa, como também um objeto de estudo para clarificar mecanismos de diversas doenças complexas, o que garante uma versatilidade mais abrangente ainda.

Com a expansão de possibilidades na utilização da CRISPR-Cas9, houve um aumento considerável de estudos direcionados à exploração profunda sobre a aplicabilidade da técnica e à própria funcionalidade dela. Como por exemplo, existem buscas para a redução dos Efeitos Fora do Alvo (OTEs, do inglês, Off-target effects) e outros erros durante experimentos na edição de genomas (Kimberland et. al, 2018), juntamente com o levantamento de ferramentas para previsão de atividade da CRISPR-Cas9 afim de melhorar sua precisão (Wilson et. al, 2018), e até criação de variantes de -cas9 projetadas, como a sniper-cas9 (Lee et. al, 2018) e as variantes SpG e SpRY (Walton et. al, 2020). Há que destacar as investigações feitas acerca dos requisitos diferentes de sequência do Motivo Adjacente de Protoespaçador (PAM, do inglês, protospacer adjacent motif), que funciona como um identificador molecular para a enzima Cas9 se agarrar e é um componente de direcionamento essencial que distingue o próprio DNA bacteriano do não próprio (Gasiunas et. al, 2020). Tudo isso contribui para um melhor entendimento dos atributos fundamentais que ainda permanecem incertos, colaborando para a confiabilidade da utilização em laboratórios, divulgação dos atributos benéficos da terapia gênica e melhorias das ferramentas baseadas em -cas9 para edição genética (Peng et. al, 2016).

Juntamente ao entusiasmo crescente no meio científico sobre as possibilidades "até-agora-infinitas" da CRISPR-Cas9, houve um aumento de bibliografias direcionadas à cura de doenças, o que não é novidade visto que, em primeira instância, as modificações genéticas em animais e indivíduos são priorizadas para esse mesmo fim. Assim, o aumento exponencial de revisões bibliográficas e pesquisas em campo sobre a utilização da CRISPR-Cas9 na inibição, ativação ou modificação de genes para o tratamento ou fortalecimento do sistema de defesa do organismo é fortemente notório no meio acadêmico. No tratamento do HIV (Nogueira, 2021), por exemplo, já é possível afirmar que a utilização da técnica diminui a carga viral até à eliminação do vírus latente, auxiliando no fortalecimento de uma possível reinfecção. Graças a pesquisas como essa, que foi possível descobrir que, ao inviabilizar o receptor CCR5, é possível adquirir imunização contra o vírus HIV desde o embrião. A técnica que edição genômica permitiu também a capacidade de correção da mutação que causa anemia falciforme, emergindo como tratamento promissor para tal doença (Mataveia, 2020; Ferreira e Gouvêa, 2018). No tratamento contra o câncer, a CRISPR-Cas9 fornece "[...] uma tecnologia eficiente para dissecar mecanismos de tumorigênese, identificar alvos para o desenvolvimento de medicamentos e, possivelmente, preparar células para terapias baseadas em células.” (Zhan et. al, 2019), porém exigirá uma investigação experimental vasta para compreender totalmente os mecanismos biológicos subjacentes às muitas interações genéticas. Até para o tratamento da Diebetes Mellitus tipo I os estudos constataram um futuro promissor para o tratamento e cura com a utilização da CRISPR (Silva et. al, 2020). Pode-se concluir que a solução para as doenças que até então eram vistas como incuráveis começaram a mostrar sinais de esperança de tratamento e cura graças à praticidade $\mathrm{e}$ eficiência da CRISPR-Cas9 na terapia gênica. A investigação profunda deste tema gera cada vez mais inspiração para novos trabalhos a ser realizados. O grande percalço disto tudo é a questão da bioética.

De acordo com Renata Ferrari (2019), a bioética é "um o estudo sistemático das dimensões morais - incluindo visão moral, decisões, condutas e políticas - das ciências da vida e atenção à saúde, utilizando uma variedade de metodologias éticas em um cenário interdisciplinar." Trata-se do exercício positivo de investigações e intervenções na saúde pública e global para a apuração de estudos voltados para a ciência clínica (Ferreira e Felipe, 2019). Por ser voltada para as boas práticas legais das pesquisas em saúde pública, a bioética diverge especialmente na área científica que mais constata desenvolvimento: a genética, sobretudo no que se refere a qualquer modificação de genes humanos para prevenção ou tratamento de doenças. O foco particular dos pesquisadores nesse quesito é a persistência de assegurar que os benefícios sejam superiores aos prováveis malefícios da engenharia genética (Vieira et. al, 2020). A maior preocupação centra-se nas próprias aplicações que uma tecnologia capaz de alterar o genoma humano consegue fazer, e particularmente se for pensar que a supressão de genes 
maléficos seja apenas uma desculpa para algo muito pior, o que trouxe de volta para a atualidade o longo debate sobre o melhoramento genético humano. (Santaló, 2019; Bergel, 2017). As questões futurísticas sobre uma sociedade utópica com seres humanos perfeitos deixaram de ser mera imaginação e está cada vez mais perto da nossa realidade principalmente com o avanço tremendo da engenharia genética proporcionado pela CRISPR-Cas9 e a suposição da criação de "super-humanos", com a exclusão notória daqueles que não são modificados. Ainda assim, é inegável o potencial benéfico que tudo isso até agora trouxe, representando um grande marco para a pesquisa e para a humanidade (Costa \& Campos, 2021), pois a terapia gênica deu um salto enorme para a frente com um arsenal cada vez maior.

A terapia gênica é "um procedimento destinado a introduzir em um organismo genes selvagens para substituir genes mutados, através do uso de técnicas de DNA recombinante" (Castro, 2020). É um melhoramento genético em que um gene normal substitui um gene anormal causador de doença, onde a ferramenta de edição genética que mais se destaca é a CRISPRCas9 cujo desenvolvimento até os dias de hoje vem trazendo enormes benefícios de valor científico no campo terapêutico (Belo et. al, 2020). De acordo com Gonçalves et. al (2017) os "sucessos pontuais já solidificam a viabilidade de tratamentos por terapia gênica na prática clínica, sendo uma forma alternativa para pacientes com doenças congênitas ou desordens monogênicas e câncer, especialmente quando as intervenções farmacológica ou cirúrgica não apresentam bons resultados". Os estudos recentes mostram que cada vez mais cresce o número de pesquisas de alelos causadores de doenças em seres vivos utilizando a CRISPR-Cas9, aumentando a esperança para o futuro da terapia gênica (Savić \& Schwank, 2016). Com a grande dificuldade para curas de doenças genéticas no mundo, a terapia genica juntamente com sistema da CRISPR-Cas9 e a evolução da tecnologia, vem se transformando no futuro do tratamento de diversas patologias, e com isso, passa a ser bastante promissor para o tratamento de diversas doenças, além da sua utilização em outras áreas que são de grande necessidade da humanidade (Sganzerla e Pessini, 2020).

No Brasil, a realidade da terapia gênica mostra que mesmo tendo já passados mais de duas décadas desde a aprovação do primeiro teste genético, ainda não foram obtidos resultados satisfatórios. Ainda assim, a esperança é o sucesso da transferência e correção de genes, beneficiando a sociedade e renunciando aos procedimentos terapêuticos atuais ineficazes ou até mesmo inexistentes (Rabelo e Júnior, 2018). A conclusão mais pacífica que os pesquisadores e a bioética puderam chegar foi a de haver uma concordância entre o biodireito e a terapia gênica à luz do conhecimento da sociedade, pois será a futura geração que sofrerá as consequências das posições que são tomadas hoje (Macedo, 2020; Pires, 2021).

\section{Conclusão}

A CRISPR-Cas9 é, portanto, uma técnica importantíssima para o futuro das edições genéticas e terapias gênicas, capaz de revolucionar toda a ciência com uma tecnologia que está ao alcance e que pode trazer inúmeros e inimagináveis benefícios para a medicina. Apesar da sua simplicidade e eficiência sendo cada dia mais e mais comprovadas, os riscos do mau uso são iminentes e não podem ser ignorados pelo simples entusiasmo científico de uma "cura para tudo". Não há como ignorar o iminente risco de ocorrer um desbalanceamento sem precedentes na sociedade caso haja desregulamentação ou acesso ilimitado às tecnologias da edição de genes. O controle legal e a viabilização da reprodutibilidade em laboratórios de pesquisa brasileiros, amparados e supervisionados por leis eficientes, podem mostrar resultados benéficos no avanço científico do país, que se encontra já em desvantagem em relação a outros países no quesito de edições genéticas. Com isso, precisa-se da interação positiva e saudável interdisciplinar da bioética, direito, biomedicina e genética, para o avanço benéfico da terapia gênica tanto no Brasil quanto no mundo, abandonando as técnicas rudimentares, dispendiosas, ineficazes e de conclusão indeterminada que a farmacoterapia têm a oferecer a pacientes de doenças congênitas e relacionados.

Considerando as questões apresentadas nas publicações e as hipóteses levantadas, faz-se necessário cada vez mais a exploração deste assunto em revisões integrativas, pesquisas bibliográficas e pesquisas de campo para despertar à população 
científica o efeito benéfico que a terapia gênica tem a oferecer, mediante as investigações já realizadas que cumprem as medidas e diretrizes da bioética.

\section{Referências}

Barboza, C. M. S., Terra, M. M., Ribeiro, M. L. C., \& Silva, J. B. (2020). A técnica de CRISPR-Cas9 na terapia gênica: uma revisão da literatura. Revista Transformar, 14(1), 562-698.

Belo, T. C. A., Paiva, P. M. H. \& Delú Filho, N. (2020). A aplicação da técnica de Edição de Genomas CRISPR-CAS9 na Engenharia Genética: benefícios à ciência e sociedade e impasses éticos frente ao desconhecido, em especial na edição embrionária humana.

Bergel, S. D. (2017). O impacto ético das novas tecnologias de edição genética. Revista Bioética, 25, 454-461.

Cronin, M. A., \& George, E. (2020). The why and how of the integrative review. Organizational Research Methods, 1094428120935507.

da Costa, M. M., de Campos Brito, T. M. \& Castro, F. A. V. (2021). Discussões éticas para a tecnologia CRISPR-Cas9. Episteme Transversalis, 12(2).

da Silva, M. R. F., Souza, K. S., Santos, M. D. V., Leite, K. M., dos Santos Silva, J., da Silva, D. C. B., \& de Oliveira, M. B. M. (2020). CRISPR/Cas9 como perspectiva de cura para o Diabetes mellitus tipo 1. Research, Society and Development, 9(12), e9691210709-e9691210709.

de Castro, J. D. C., \& Montardo, E. C. (2020, June). O avanço da terapia gênica no tratamento de doenças. In X Mostra Integrada de Iniciação Científica.

de Sousa, L. M. M., Marques-Vieira, C. M. A., Severino, S. S. P., \& Antunes, A. V. (2017). A metodologia de revisão integrativa da literatura em enfermagem. $N^{\circ} 21$ Série 2-Novembro 2017, 17.

Dias, C. A. D. P. \& Dias, J. M. R. (2018). O Sistema CRISPR-CAS como uma nova ferramenta biotecnológica na edição de genomas: aplicações e implicações. Rev. Ambiente Acadêmico, 4(1).

dos Reis, G. R., Moraes, J. V. D. L., da Silva, L. L., de Carli, N. M., \& Smiderle, L. (2020, June). CRISPR-Cas9: a Tecnologia do Novo Mundo. In X Mostra Integrada de Iniciação Científica.

Doudna, J., \& Charpentier, E. The war on cancer betrayed by nature. Monthly Archives: December 2020. https://cancerforall.wordpress.com/2020/12/

Fernandes, A. R. L. (2020). Relatórios de Estágio e Monografia intitulada" Sistema CRISPR/Cas9: Uma Abordagem Terapêutica Inovadora no Tratamento de Patologias Humanas" (Doctoral dissertation, Universidade de Coimbra).

Ferrari, R. R. (2019). Princípios Da Bioética. In Totum-Periódico de Cadernos de Resumos e Anais da Faculdade Unida de Vitória, 4(1).

Ferreira, P., \& Filipe, Â. M. (2019). Bioética. Dicionário Alice.

Ferreira, R., \& Gouvêa, C. M. C. P. (2018). Recentes avanços no tratamento da anemia falciforme.

Gasiunas, G., Young, J. K., Karvelis, T., Kazlauskas, D., Urbaitis, T., Jasnauskaite, M., \& Siksnys, V. (2020). A catalogue of biochemically diverse CRISPRCas9 orthologs. Nature communications, 11(1), 1-10.

Gonçalves, G. A. R., \& Paiva, R. D. M. A. (2017). Terapia gênica: avanços, desafios e perspectivas. Einstein (São Paulo), 15(3), $369-375$.

Gonzaga, G. C., \& Ramos, C. (2018) Técnica CRISPR-Cas9 e sua utilização na Área Laboratorial.

Kimberland, M. L., Hou, W., Alfonso-Pecchio, A., Wilson, S., Rao, Y., Zhang, S., \& Lu, Q. (2018). Strategies for controlling CRISPR/Cas9 off-target effects and biological variations in mammalian genome editing experiments. Journal of biotechnology, 284, 91-101.

Le Rhun, A., Escalera-Maurer, A., Bratovič, M., \& Charpentier, E. (2019). CRISPR-Cas in Streptococcus pyogenes. RNA biology, 16(4), 380-389

Lee, J. K., Jeong, E., Lee, J., Jung, M., Shin, E., Kim, Y. H., \& Kim, J. S. (2018). Directed evolution of CRISPR-Cas9 to increase its specificity. Nature communications, 9(1), 1-10.

Lins, A. A., Mello, P. L., \& Gonçalves, F. B. (2018). Edição genética associada ao uso da nova técnica CRISPR/Cas9, ferramenta de defesa utilizada pelas bactérias contra DNA invasor. Revista Eletrônica Científica Da UERGS, 4(3), 358-367.

Macedo, A. L. (2021). A importância da bioética e do biodireito no campo da manipulação genética.

Mataveia, E. R. F. (2020). Aplicabilidade clínica da técnica CRISPR-Cas9 (Clustered Regularly Interspaced Short Palindromic Repeats) no tratamento da anemia falciforme: uma revisão integrativa.

Mendes, K. D. S., Silveira, R. C. D. C. P., \& Galvão, C. M. (2019). Uso de gerenciador de referências bibliográficas na seleção dos estudos primários em revisão integrativa. Texto \& Contexto-Enfermagem, 28.

Nascimento, J. (2020). Bioética e tecnologia. Revista Batista Pioneira, 9(2).

Nogueira, R. F. S. (2021). CRISPR-Cas9 against HIV infection.

Peng, R., Lin, G., \& Li, J. (2016). Potential pitfalls of CRISPR/Cas9-mediated genome editing. The FEBS journal, $283(7)$, $1218-1231$. 
Pires-Oliveira, T. (2021). Fragmentos de um discurso biocolonizador no Projeto Genoma Humano: direito, patrimônio genético e vulnerabilidade. Revista Direitos Fundamentais e Alteridade, 4(1), 50-79.

Rabelo, A. C., \& Júnior, J. B. (2018). Realidades e perspectivas do uso de terapia gênica no tratamento de doenças. Revista da Faculdade de Ciências Médicas de Sorocaba, 20(3), 122-127.

Santaló, J. (2019). La mejora genética humana en los tiempos del CRISPR/Cas9. Revista de Bioética y Derecho, (47), 33-41.

Savić, N., \& Schwank, G. (2016). Advances in therapeutic CRISPR/Cas9 genome editing. Translational Research, 168, 15-21.

Sganzerla, A., \& Pessini, L. (2020). Edição de humanos por meio da técnica do Crispr-cas9: entusiasmo científico e inquietações éticas. Saúde em Debate, 44, 527-540.

Sganzerla A, \& Pessini L - Saúde em Debate, 2020 - SciELO Public Health

Vieira, L. T. Q., da Mata, G. H. C., de Souza Calvoso, B., Ferreira, V. L. F. A., \& do Amaral, W. N. (2020). A bioética e a genética humana. REVISTA BIOÉTICA CREMEGO, 2(2), 12-15.

Walton, R. T., Christie, K. A., Whittaker, M. N., \& Kleinstiver, B. P. (2020). Unconstrained genome targeting with near-PAMless engineered CRISPR-Cas9 variants. Science, 368(6488), 290-296.

Wilson, L. O., O’Brien, A. R., \& Bauer, D. C. (2018). The current state and future of CRISPR-Cas9 gRNA design tools. Frontiers in pharmacology, 9 , 749.

You, L., Tong, R., Li, M., Liu, Y., Xue, J., \& Lu, Y. (2019). Advancements and obstacles of CRISPR-Cas9 technology in translational research. Molecular Therapy-Methods \& Clinical Development, 13, 359-370.

Zhan, T., Rindtorff, N., Betge, J., Ebert, M. P., \& Boutros, M. (2019, April). CRISPR/Cas9 for cancer research and therapy. In Seminars in cancer biology (Vol. 55, pp. 106-119). Academic Press. 